\title{
Studying the Accounting Information Role for the Industrial Companies' Attitudes towards the Implementation of Total Quality Management System (Syrian Case)
}

\author{
Dr. Mohyedin Hamza ${ }^{1} \&$ Dr. Talal AL- Kassar ${ }^{2}$ \\ ${ }^{1}$ Associate Professor, Department of Accounting, Faculty of Economics and Administrative Sciences, Zarqa \\ University, P.O. Box 132222, Zarqa 13110, Jordan \\ ${ }^{2}$ Associate Professor, Department of Accounting, Faculty of Economics and Administrative Sciences, Zarqa \\ University, P.O. Box 132222, Zarqa 13110, Jordan \\ Correspondence: Dr. Mohyedin Hamza, Associate Professor, Department of Accounting, Faculty of Economics and \\ Administrative Sciences, Zarqa University, P.O. Box 132222, Zarqa 13110, Jordan. E-mail: \\ mohy.hamza@yahoo.com
}

Received: February 1, 2015

Accepted: February 19, $2015 \quad$ Online Published: March 9, 2015

doi:10.5430/afr.v4n2p34

URL: http://dx.doi.org/10.5430/afr.v4n2p34

\section{Acknowledgements}

Special thanks to Zarqa University for supporting this research.

\begin{abstract}
The ever-increasing importance of industrial companies in Syria coupled with global and domestic competitions, increasing cost and decreasing profitability was the impetus for this study. This study aimed to know the accounting information role towards the attitudes of the Syrian industrial companies towards the applying of total quality system. Through identifying of the response and support companies efforts towards this system; the availability of requirements that need to these companies to apply the system, identify the obstacles that might hinder the application process, and the impact of the application of this system in the performance of these companies. In order to achieve this primary objective, the researchers have studied the intellectual frame and scientific rooting for the total quality management system (TQM). The researchers designed a questionnaire aimed to execute field study of the study problem variables in order to test hypotheses; the study population consisted of a group of industrial companies working in the Syrian Arab Republic. The researchers suggested the following results: the application of total quality management system lead to many benefits for companies that are applied it have represented in improving the competitive position, increasing market share, increasing production efficiency, and reducing cost. The field study reversed many results. These are a statistically significant relationship to the role of accounting information towards the attitudes of the study sample towards the response and supporting of industrial companies to total quality system. In addition to the availability requirements of the application of total quality management system in industrial companies, obstacles of the application of total quality management system in industrial companies, and the impact of the application of total quality management system in the performance of industrial companies. Finally, the study recommended that necessity of the operating companies in Syria, whether in the public sector or the private sector to seek towards the implementation of total quality management system.
\end{abstract}

Keywords: Accounting information, TQM system, Industrial companies

\section{Introduction}

The utilization of Total Quality Management (TQM) has become more popular in today's business organizations than before, and TQMs adoption by industries has increased over the years (Al-Kassar \& Ahmed, 2013). The concept of total quality management methods, which had been in great demand worldwide management, and since the beginning of the announcement of this concept in the fifties of the last century in Japan. It applied by Japanese companies overall quality management system since the beginning of the second half of the twentieth century, with the aim of solving productivity problems and improve quality. Existing research has noted that in the early years prior to the1950's, emphasis to achieve significant economic savings (cost reduction) in operations equivalent to fold what can be achieved by increasing the annual sales alone (Alwan, 2005). 
The contemporary world is going through a technical and social changes are enormous, all of which affect the performance of the business method strongly, not only in the global markets, but also in the local markets, which are becoming more open to global competition (Al-Kassar and Ahmed, 2013). This competition has become, in recent years, an important factor to companies that want to be in superiority and to provide best products depending on accurate accounting information (Kandil, 2008).

Because of this competition, some companies have threatened to get out of the market unless you can and optimally to meet the many requirements relating to product quality and innovation of new types of products and others. Also failed to old management styles to meet the needs of customers and users of the company's products or services (Neogy, 2014). All those previous reasons paved the way for the emergence of modern methods of management Perhaps the most important of the overall quality, which is the most important stages of the development of quality, in terms of TQM formed a new and effective administrative concept to all companies (Shibley, 2006). This concept has contributed to the achievement of management objectives. Even it became the age feature and focus of attention of many companies that want to achieve their goals. Where it worked for TQM to help companies apply them and enabled them to respond to the challenges faced and overcome, and the promotion of local and global competitiveness (Al-Safar and Mohammed, 2008). It reflected positively on the state of performance and productivity have, and high customer satisfaction, and increase sales volume and thereby increase their profits and increase market share (Al-Tai, and Kdadh, 2009).

Accounting Information are collects and processes data, which has measured in terms of money. Its process accounting transactions and supplies information for the interested users, which has used to take effective decision-making process, to help management for performing business activities properly and finally to measure the performance of the company. AIS are the oldest and most wide used information systems in business. Accounting is primarily concerned with the design of the system of records, the preparation of reports based on the recorded data, and the interpretation of the reports to the both internal and external users for making decision. Accounting system is a recording process system like journal, ledger, worksheet, trial balance and procedures that are produced reliable and relevant information for preparing the financial statements and other accounting reports for the satisfaction of the different users to effective decision making. Modern world is the information world and every business organization makes it necessary to obtain proper information both for external and internal users for appropriate decision-making. The accounting system is an integral part of the internal control structure of an organization. Without the information generated by accounting, management would lack the ability to plan and direct operations in achieving organizational goals. Although the availability of computer has made computerized processing of accounting data affordable to any organization, a thorough understanding of manual accounting system is essential. All computerized accounting systems include the concepts and principles inherent in a manual system; an understanding of a manual system allows managers to recognize more clearly the interrelationships, which exist within accounting data, and reports. (Kieso, et al, 2013).

According to the great importance gained by total quality management in the modern manufacturing environment, particularly because of its appropriate tools and methods make her an influential role in raising the administrative efficiency and productivity and development effectiveness, efficiency, flexibility and competition in any company, the focus clearly on the needs of the markets in which companies operate. The researchers have formulated research problem in the next major question. What is the role of accounting information for trends Syrian industrial companies towards the implementation of total quality management system?

The important of the research are:

- to highlight the role of accounting information for TQM in support of companies towards achieving its objectives، namely to grow and survive.

- to find in many aspects related to the overall quality of the hand. the study of trends in the management of industrial companies about the application of TQM support and benefit from their efforts in supporting the continuous improvement of their process .

Therefore, this paper attempts to fill the gap by studying the aims mainly to see trends in Syrian industrial companies about the following:

- Response and support of these companies for the application of total quality management.

- The availability of the application of TQM in those industrial companies' management requirements.

- The obstacles that hinder the successful implementation of total quality management from the perspective of the study sample. 
- The impact of the application of accounting information to total quality management in the performance of these industrial companies.

\section{Research Methodology}

The researchers in order to achieve the objectives depend and testing of hypotheses on the deductive approach, as will the researchers access to the literature and research and previous studies that are relevant to the subject of the study, in order to configure the theoretical framework of the research, and form the basis of intellectual and theoretical subject under study. The researchers will conduct the field study through a questionnaire will be distributed to a sample of the population of the study and will test the hypotheses and analyze the results using the Computer Using statistical package of social sciences (SPSS).

\subsection{Research Hypotheses}

The study hypotheses were as follows:

$\mathrm{Ho}_{1}$ : There are no statistically significant relationship trends in the study sample towards the response and support to total quality management in industrial companies.

$\mathrm{Ho}_{2}$ : There are no statistically significant relationship trends in the study sample about the availability of the application and its requirements to total quality management in industrial companies.

$\mathrm{Ho}_{3}$ : There are no statistically significant relationship trends in the study sample about the obstacles of the application with its tools to total quality management in industrial companies.

$\mathrm{Ho}_{4}$ : There are no statistically significant relationship trends in the study sample about the impact of the application of accounting information for improving performance to total quality management in industrial companies.

\subsection{Study Model}

The model of the study is below:

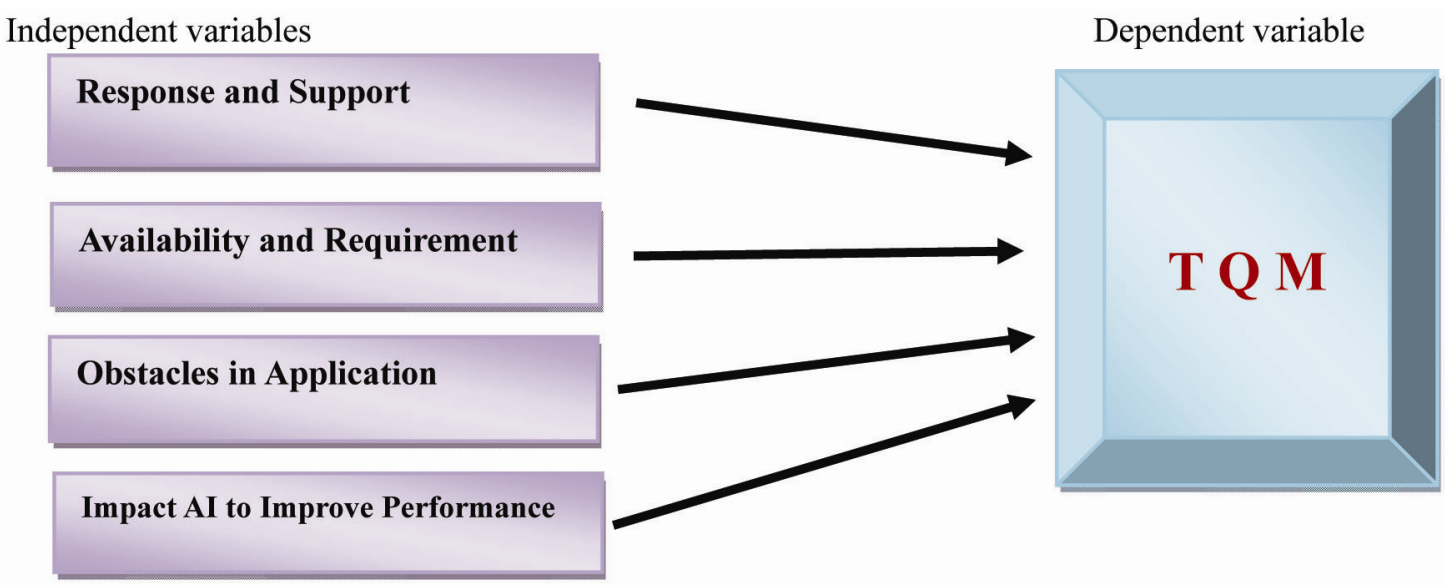

\section{Literature Review}

\subsection{Previous studies}

There exists a broad frame of research developed, especially "between" (2006-2014). Many research studies looked at the subject of the role of accounting information for industrial companies' attitudes towards the implementation of TQM, and some of these studies are:

Neogy study, (2014), "Evaluation of Efficiency of Accounting Information Systems: A Study on Mobile Telecommunication Companies in Bangladesh". The study evaluates the efficiency of Accounting Information Systems of the selected mobile telecommunication companies. The existing Accounting Information Systems, which provide important sources of accounting information, has viewed in the selected mobile telecommunication companies, more as the system for recording and reporting the business operations than as an information system for management decision making. Al-Kassar and Ahmed study, (2013), "Scientific approach for quality audit to service and productivity enterprises (Applied study in Zarqa University)". This research is dealing with an important side of the comprehensive performance evaluation of enterprises, especially with the quality of service. The objectives of research may consider through the need to set up a program to use for evaluation the steps of special auditing to quality. In addition, the program should carried out and developed any change according to the 
situation under consideration. Al-Safar and Mohammed study, (2008), entitled "The impact of the application of the philosophy of total quality management in accordance with the internal and external customer perspective on the operating performance of the manufacturing organizations". This study aimed to identify the impact of the application of the philosophy of total quality management in accordance with the internal and external customer perspective on the operating performance of the manufacturing organizations, and through the measurement of the extent of interest in managing the organization of internal and external customer and its impact on performance. The study has applied to Petra Engineering Industries Co. the company applied for TQM and holds a King Abdullah II Award for Excellence in Jordan. To achieve the objectives of the study, the researcher designed a questionnaire aimed to conduct field study, where the distribution (70) questionnaire on the study sample was subjected to (60) including a questionnaire for the study. Kandil study, (2008), entitled "The impact of the application of total quality at competitive policies in the industrialized enterprises Empirical Study on the industrial sector enterprises in the Gaza Strip". The study has applied at the Palestinian industrial sector companies. It aimed to study the impact of the application of total quality and competitive policies in the Palestinian industrial company's management system variables, as well as to recognize the reality of TQM in the Palestinian industrial company's management system, and to identify competitive policies pursued by these companies. To achieve the objectives of the study, the researcher designed a questionnaire aimed to make a field study of the variables of the study the problem. In order to test hypotheses, where the study population consisted of working in senior management in companies. The researcher has distributed 121 questionnaires to companies under study. The valid of them were (110) questionnaires to conduct the study. The study has reached many findings. Matari study, (2007), entitled "The impact of the application of total quality management (TQM) in the development of systems effectiveness. An Empirical Study of the industrial sector in the Republic of Yemen". This study has applied to a sample of companies and institutions working in the industrial sector in the Republic of Yemen, the letter aimed at the following: study and analysis of the reality of the industrial environment in Yemen. One of the important findings of this study: there is no real application of the quality system costs, in addition to a lack of cost-based systems, and they are not eligible for the application of the system. Shibley study, (2006), entitled "The possibility of the application of TQM in the Iraqi industrial organization management - a prospective study in the General Public Company for petrochemical industries". This study aimed to detect the possibility of the application of TQM in the Iraqi industrial management of the company, the study has conducted at the General Public Company for Petrochemical Industries. To conduct the study, the researcher based on deductive approach based on logical analysis to show how fit large and small Iraqi industrial organizations with the principles of total quality management. A questionnaire was design, which included (28) items and distributed to a sample study, which measure the level of awareness of the Iraqi industrial companies to the principles of total quality management. Al-Hashmi study, (2006), entitled "TQM principles and their impact in determining the competitive priority - Empirical Study of Kufa in the new cement plant". This study aimed to determine the impact of the application of the principles of total quality management in determining the competitiveness precedents in Kufa new cement plant. The most important findings of this study: the presence of a great interest by the senior management of the company under study to the principle of focusing on the customer by gaining satisfaction through the provision of high-quality product at a reasonable price. In addition to the senior management of the company researched pay attention great principle of continuous improvement of its activities

Through a review of the various subject of previous studies, we find that this study converge with previous studies to highlight the important role that can be played by TQM in the field to maintain a competitive advantage and reduce costs and achieve operational effectiveness. While this study differs from previous studies in being will look at several aspects related to the application of total quality in industrial companies operating in Syria management system, and this is what distinguishes it from many of the studies. Where the focus of this study is not only on trends of industrial companies about the availability of the application of total quality management requirements, but also focuses on the role of accounting information in identifying trends in industrial companies. Other aspects relating to the application of total quality management in response and support industrial companies, impediments to the application, and the impact of the application the successful performance of the industrial companies have been included.

\subsection{Introduction to Total Quality Management}

The concept of total quality management methods, which had been in great demand worldwide management, and since the beginning of the announcement of this concept in the fifties of the last century in Japan. It applied by Japanese companies overall quality management system since the beginning of the second half of the twentieth century, with the aim of solving productivity problems and improve quality. The practical application of this method 
is proved that from which to achieve significant economic savings (cost reduction) in operations equivalent to fold what can be achieved by increasing the annual sales alone (Alwan, 2005). The phenomenon of Japanese economic success has increased of interest in both industrialized countries and countries developing; the application of this system, given for his great success for companies that have acted, and what could access it from hand to satisfy customers and continuous improvement in performance and work as a team in those companies. However, this concept appeared as the title of a comprehensive modern management philosophy through the nineties of the twentieth century, so that the economic life of corporate style and approach to compete and survive in the market has become. This method, which means that the only acceptable level of quality is there are no defects at all (Zero defects), was envisaged at the beginning of the matter is that the achievement of this distant goal -fetched. However, the companies have made him a target level of quality has worked to achieve year after year, until now a reality (Hussein, 1997). In spite of some difficulties that accompanied the application of the concept of total quality management, as required of patience and hard work for several years, but it is today much stronger than it was in the past, where there is not a method of statistical measurements of defects and conduct the examination, inspection and debugging processes. It has become a comprehensive concept reflects the client's feelings about the product or service, and focus on all the operations and activities of daily production (Abu-Nasr, 2008).

\subsection{TQM Meaning}

Many authors and researchers have disagreed about the status of a specific definition of total quality management, since the quality alone carry many of the concepts according to the viewpoint of each researcher, and therefore, it cannot find TQM specific and comprehensive definition.

Kelada (2004), was defined it as, "It is a way of thinking to apply that which assumed by all individuals within the organization as well as external. In addition, be this philosophy geared to profit, and focused on the customer, and centered around people, and help her partners, and aware of the environment, working all individual as a team headed by an Executive Director, who shall be responsible for the overall quality goal. The International Organization for Standardization has defined as "Introduction to the management of the organization, based on quality, built on the participation of all its members, is aimed at long-term success through customer satisfaction, and achieve benefits for all members of the organization and the community (Abu-Nasr, 2008). While Naidu et al., (2006) defined as "promote the traditional way of doing business, a method installed to ensure survival in the competition at the global level, just by changing the actions of management that will lead to changes in the culture and the actions of the entire company,". Joseph Jablonski (1996) defined as "a cooperative form of doing business depends on the abilities and talents for each of the management and staff to improve the quality and productivity continuously by working teams". Goran sees it:" developed a set of tools that can be applied effectively to the company's management system, to bring about changes in the attitudes of employees, and increase their affiliation to the company "(Khashoggi, 2003).

Through what has review of definitions related to TQM, it can be defined as follows "a management system based essentially on continuous improvement in all activities of the company, through the application of strategic (long-term) a comprehensive focus on the client inside and outside the company. By building team depends on able to employ their abilities and talents and experience of collective method for achieving the goals of this system, finding new ways to adapt to the environment variables, business performance correctly the first time and without errors, thus achieving the ambition of these companies in improving the global competitiveness."

The application of the principles of TQM in companies require of these companies are working to create the appropriate and necessary conditions in order to achieve a satisfactory and effective results management process, and therefore must be for these companies to provide a set of requirements that interact with each other for total quality management to successfully apply them. Through a review of the literature and the various references, including: (Jouda, 2004), (Williams, 1999), (Taei et al., 2009), (Alwan, 2005), (Haddad, 2009). It has many of the requirements was found to achieve the principles of total quality management, and these requirements vary among researchers in number only, but they are consistent with each other in terms of substance and content. These requirements include the following:

- Leadership.

- Support from senior management.

- Work teams .

- Effective design of goods and services .

- Focus on processes. 
- Establish standards of performance.

From the researchers point of view to provide the above requirements is the process is essential to the process of starting the application of total quality management, and overall quality in order to achieve success for the company.

TQM is gaining great importance in the provision of these requirements, the process may not be over a short period, but it may need a large and long-time effort to require the concerted efforts of all to achieve in order to reach these requirements. In addition, start applying modern manufacturing environment management, and private companies including accomplish that work on the application, and highlights the importance of the application of total quality management through the following:

1. One of the ways to develop the effectiveness and efficiency, flexibility and competition in any company, is to eliminate any excess through participate all individuals in the development of the methods that are out tasks. It also helps companies to continuous assessment of the operations to be able to develop a strategy for continuous development (Sever, 2007).

2. Reduce customer complaints through the full understanding of their needs and work to achieve them (Al-Hashimi, 2006).

3. Works to achieve the benefits of multiple savings in costs and timelines of production processes, thus contributing to raising the quality level of products (Ben Antar, 2008).

TQM aims to achieve the following:

1. Customer Satisfaction: Customer satisfaction has achieved through the realization of their requirements down or even when they are exceeding their expectations.

2. Improve the team's efforts and staff: Management should work to improve the work and the areas of personnel team's efforts. In order to achieve the goals and objectives of the company, where he must work to remove barriers internally between levels of management; between departments and within departments, they must all work together, through open channels of communication with each other. As well as the need to work on the organization and training of these teams (Naidu et al, 2006).

3. Continuous Improvement: It has based on the idea that any aspect of the process can improved, and that the individuals who are associated with significantly the process they are in the best position to determine the changes that should made, that is not to wait until the problem is exacerbated by the decision. It can focus on continuous improvement problems with customers and suppliers, as well as to reduce the length of time required to process and other (Haddad, 2009).

There are many advantages that can achieved by total quality management for companies applied to her, remember the most important (Alwan, 2005) (Haddad, 2009):

1. Strengthen the competitive position of companies by focusing on providing products or high quality services to customers, and thus increase production and reduce costs.

2. Reduce and mastery of administrative processes within the company.

3. Continuous improvement of the whole process undergone by the products and focus on results.

4. Increase market share for companies that apply total quality management, and steadfastness in the face of competition and market volatility.

5. Increase the efficiency and productivity by reducing waste and loss in inventory, reduce errors and operational processes, reducing the number of times and the costs of modifying designs, simplifying forms and procedures, improve the working environment and to promote team spirit, and work to reach the maximum production capacity as soon as possible.

Thus, the researchers find that companies must apply total quality management in an effective manner, working to identify the obstacles that stand in their way, analyzing and working to remove them. This will lead companies get up to the desired application of the results.

\section{Study Instrument}

After completion of the study to determine problems, and hypotheses, the researchers prepared a questionnaire study. That covers all variables model study, which included a questionnaire study in its final form to the following parts: 


\subsection{Sampling}

The researchers were selected a sample study of (12) companies of industrial companies operating in the Syrian Arab Republic. Specifically in the provinces of Damascus and its countryside. These are (4) companies in pharmaceutical industry, (5) companies in manufacturers of food, (1) chemical industry and (2) industry materials companies Beitunia. The researchers were distribute of the questionnaire for each of the (Executive Director, quality manager, quality control, production manager, chief financial officer (CFO) and accounting costs for each company).

\subsection{Data collection}

At this stage, the researchers adopted a questionnaire as a means to gather information that will help in achieving the objectives of the research, the questionnaire has divided the list into two parts (see Appendix No. 1) in the following form :

The first part includes the study objectives and scope, as well as data related to general information about the research sample companies, as well as private information concerning individual's sample (see Table 2).

The second part includes a set of questions related to the knowledge of the views of the industrial economic units under study about the availability requirements that companies need to apply TQM system, and to identify the views of these units about the impact of the application of this concept in corporate performance.

\subsection{Study Instrument scale}

Five points Likert scale has been selected, for being one of the most metrics used to measure the opinions and responses, due to its ease of understanding, indicates where the study sample under test for the extent of their agreement for each paragraph of the questionnaire as follows:

\begin{tabular}{|l|l|l|l|l|}
\hline Strongly Agree & Agree & Not sure & Disagree & Strongly Disagree \\
\hline 5 & 4 & 3 & 2 & 1 \\
\hline
\end{tabular}

The study population consists of (12) companies. The study sample of general managers and directors of administrative units and financial managers, internal audit exclusively, totaling (57) questionnaires as shown below. However, what was subjected to statistical analysis only (41) because of the lack of returned or completion of the respondents, it was $(71.93 \%)$.

Table 1. the Study Population and Questionnaire Distributed

\begin{tabular}{lll}
\hline Companies & Number of Companies & No. of Questionnaire Distributed \\
\hline companies in pharmaceutical industry & 4 & 20 \\
companies in manufacturers of food & 5 & 25 \\
chemical industry & 1 & 4 \\
industry materials companies Beitunia & 2 & 8 \\
Total & 12 & 57 \\
No. of Questionnaire Subject to statistical analysis & 41 \\
Percentage & & $71.93 \%$ \\
\hline
\end{tabular}

To achieve the objectives of the study were used scale (Likert) as mentioned above. The averages were determined for the purposes of the study as follows: (4.25-5) indicate a very high degree, (3.50-4.24), indicating a high degree, (2.75-3.49) indicates a medium degree, (2-2.74) indicate the degree low (less than 2) show a very low degree .

\subsection{Statistical Techniques}

The researchers from the process of collecting data on variables model study entered the data for Computer -program for extracting statistical results needed. It was drawing on some statistical methods available in software packages Statistical Social Sciences (SPSS), in order to process the data that have obtained through the study field of the surveyed sample; specifically the researchers used statistical methods the following:

\section{-Cronbach's alpha coefficient.}

-Frequencies and percentages.

-Mean and standard deviation.

-Use Kolmogorov test - Smirnov (One-Sample Kolmogorov Smirnov Test). 
-T Test: To judge the ability to accept or reject the research hypotheses by comparing (T) calculated with a significance level (0.05), taking into account that the number of sample did not exceed (41) respondent.

-Correlation test (Spearman): to determine relationships between variables of the study questionnaire, and mutual influences between them.

\section{Results and test hypotheses:}

Test of Cronbach-Alpha: it cares about this test to determine the credibility of the list of the questionnaire and the contents, according to this test whenever approached value (alpha) of one right. The homogeneity and thus credibility, the closer the value (alpha) of zero indicates that the lack of homogeneity and thus lack credibility, and the reality of program outputs SPSS show the value of the test (alpha) as follows:

Table 2. result of the test Cronbach's alpha coefficient

\begin{tabular}{ll}
\hline No of Items & Alpha \\
\hline 23 & .859
\end{tabular}

Thus, it shows us the value of alpha (85.9\%), which indicates the homogeneity and increased credibility.

Table 3. Describe the characteristics of the study sample of managers

\begin{tabular}{lll}
\hline DESCRIBTIVE & DISTIRBUTION & \\
\hline Sex & Male & $80.5 \%$ \\
& Female & $19.5 \%$ \\
Scientific specialization & Secondary or less & $2.4 \%$ \\
& University degree & $85.4 \%$ \\
& Postgraduate & $12.2 \%$ \\
No. of Employee & Less than 50 & $17.1 \%$ \\
& $50-300$ & $63.4 \%$ \\
Years of Experience & More than 300 & $19.5 \%$ \\
& Less than 3 years & $0 \%$ \\
Is your company aims & $3-6$ & $19.5 \%$ \\
TQM? & More than 6 & $80.5 \%$ \\
& Yes & $100 \%$ \\
\hline
\end{tabular}

Table 4. One-Sample Kolmogorov Smirnov Test

\begin{tabular}{lll}
\hline Sig & Z Value & Group \\
\hline 0.0014 & 1.9902 & $\begin{array}{l}\text { How far the response and support for industrial companies to } \\
\text { Total Quality Management system } \\
\text { How far the availability requirements needed by industrial } \\
\text { companies to implement total quality management system and } \\
\text { its tools }\end{array}$ \\
0.0228 & 1.5502 & $\begin{array}{l}\text { Obstacles to the application of total quality management and its } \\
\text { tools in industrial companies } \\
\text { The impact of the application of total quality management } \\
\text { system and its tools in the performance of industrial companies } \\
\text { General Mean }\end{array}$ \\
\hline
\end{tabular}

It note from table above that the value (Sig.) for each group is less than (0.05) and therefore the data do not follow a normal distribution. 


\subsection{Results of the test first hypothesis:}

Deals with evaluating the response and support for the concept TQM to industrial companies, and consists of variables affecting the hypothesis of: $\mathrm{X} 1, \mathrm{X} 2, \mathrm{X} 3, \mathrm{X} 4$, and $\mathrm{X} 5$ (as appear in appendix).

Table 5. the results of the test (T-Test) variables associated with the imposition of the first hypothesis

\begin{tabular}{llllll}
\hline Variables code & Mean & Std. Deviation & T Value & $(\mathrm{df})$ & Significant \\
\hline X1 & 4.52 & 0.552 & 52.029 & 40 & 0.000 \\
X2 & 4.46 & 0.552 & 51.18 & 40 & 0.000 \\
X3 & 4.27 & 0.633 & 42.642 & 40 & 0.000 \\
X4 & 3.41 & 0.591 & 47.322 & 40 & 0.000 \\
X5 & 4.34 & 0.728 & 37.728 & 40 & 0.000 \\
General Mean & 4.404 & 0.6112 & 46.1802 & 40 & 0.000
\end{tabular}

It notes that the arithmetic averages of the year for the first hypothesis is (4.404) of five points. This indicates that, the response and support industrial companies of the concept of TQM was a high degree. It shows the results of the test (T) above it. It must reject the hypothesis of nowhere and accept the alternative hypothesis, where each variables of the study appear when the level of significance is less than (0.05). This is to accept the alternative hypothesis, which is; there is a statistically significant relationship trends in the study sample towards the response and support to total quality management in industrial companies.

5.1.1 Test the correlation coefficients between the studies variables associated with the first hypothesis:

The results of the table below show the strength and direction of the correlation coefficients between variables. This indicates that the proportional relationship between the variables, as well as the strength of correlation coefficients between variables is medium when the level of significance $(0.05)$ and the level of significance $(0.01)$.

Table 6. the results of the analysis of the link between some of the variables associated with the first hypothesis

\begin{tabular}{llllll}
\hline Variable Code & X1 & X2 & X3 & X4 & X5 \\
\hline X1 & & & & $.297(*)$ & \\
X2 & & & $.422(* *)$ & $.623(* *)$ & \\
X3 & & $.422(* *)$ & & & $.501(* *)$ \\
X4 & $.297(*)$ & $.623(* *)$ & & & \\
X5 & & & $.501(* *)$ & & \\
\hline
\end{tabular}

* Correlation at the level of significance $(\alpha \leq 0.05)$.

**Correlation at the level of significance $(\alpha \leq 0.01)$.

\subsection{Results of the test second hypothesis}

Deals with the judgment on the availability of the application requirements for the concept TQM to industrial companies, and consisting of variables affecting the hypothesis of: $\mathrm{X} 6, \mathrm{X} 7, \mathrm{X} 8, \mathrm{X} 9$, and $\mathrm{X} 10$ (as appear in appendix).

Table 7. the results of the test (T-Test) variables associated with the imposition of the second hypothesis

\begin{tabular}{llllll}
\hline Variables code & Mean & Std. Deviation & T Value & (df) & Significant \\
\hline X6 & 4.17 & 0.771 & 34.203 & 40 & 0.000 \\
X7 & 4.17 & 0.771 & 34.203 & 40 & 0.000 \\
X8 & 3.49 & 1.003 & 21.946 & 40 & 0.000 \\
X9 & 4.2 & 0.715 & 37.13 & 40 & 0.000 \\
X10 & 3.95 & 0.893 & 27.971 & 40 & 0.000 \\
General Mean & 3.996 & 0.8306 & 31.0906 & 40 & 0.000 \\
\hline
\end{tabular}

It notes that the arithmetic average of the year for the second hypothesis is (3.996) of five points. This indicates that availability requirements of the application of the concept of TQM in industrial companies was a high degree. It 
show the results of the test $(\mathrm{T})$ above it. It must reject the hypothesis of nowhere and accept the alternative hypothesis, where that all the variables of the study appear when the level of significance is less than (0.05). This is to accept the alternative hypothesis, which is; there is a statistically significant relationship trends in the study sample about the availability requirements of the application to total quality management in industrial companies.

5.2.1 Test the correlation coefficients between the studies variables associated with second hypothesis:

The results of the table below show the strength and direction of the correlation coefficients between variables. This indicates that the proportional relationship between the variables, as well as the strength of correlation coefficients between variables is medium when the level of significance (0.05) and the level of significance (0.01).

Table 8. the results of the analysis of the link between some of the variables associated with the second hypothesis

\begin{tabular}{llllll}
\hline Variable Code & X6 & X7 & X8 & X9 & X10 \\
\hline X6 & & $.412(* *)$ & $.697(* *)$ & & \\
X7 & $.412(* *)$ & & $.342(*)$ & $.301(*)$ & $.375(* *)$ \\
X8 & $.697(* *)$ & $.342(*)$ & & & \\
X9 & & $.301(*)$ & & & $.289(*)$ \\
X10 & & $.375(* *)$ & & $.289(*)$ & \\
\hline
\end{tabular}

* Correlation at the level of significance $(\alpha \leq 0.05)$.

**Correlation at the level of significance $(\alpha \leq 0.01)$.

\subsection{Results of the test third hypothesis}

Deals with the impact of obstacles application for the concept TQM and its tools to industrial companies, and consisting of variables affecting the hypothesis of: X11, X12, X13, X14, X15, and X16 (as appear in appendix).

Table 9. the results of the test (T-Test) variables associated with the imposition of the third hypothesis

\begin{tabular}{llllll}
\hline Variable code & Mean & Std. Deviation & T Value & (df) & Significant \\
\hline X11 & 4.1 & 0.664 & 39.061 & 40 & 0.000 \\
X12 & 3.56 & 0.743 & 30.247 & 40 & 0.000 \\
X13 & 3.88 & 0.64 & 38.292 & 40 & 0.000 \\
X14 & 3.66 & 1.039 & 22.229 & 40 & 0.000 \\
X15 & 4.27 & 0.663 & 42.642 & 40 & 0.000 \\
X16 & 4.34 & 0.693 & 39.642 & 40 & 0.000 \\
General Mean & 3.968 & 0.735 & 35.35217 & 40 & 0.000 \\
\hline
\end{tabular}

It notes that the arithmetic average, of the year for the third hypothesis is (3.968) of five points. Which indicates the existence of obstacles to the application of total quality management and its tools in industrial companies with a high degree. It show the results of the test $(\mathrm{T})$ above it. It must reject the hypothesis of nowhere and accept the alternative hypothesis, where the all the variables of the study appear when the level of significance is less than (0.05). This is to accept the alternative hypothesis, which is; there is a statistically significant relationship trends in the study sample about the obstacles of the application to total quality management and its tools in industrial companies.

5.3.1 Test the correlation coefficients between the studies variables associated with the third hypothesis

The results of the table below show the strength and direction of the correlation coefficients between variables. This indicates that the proportional relationship between the variables, as well as the strength of correlation coefficients between variables is medium when the level of significance $(0.05)$ and the level of significance $(0.01)$. 
Table 10. the results of the analysis of the link between some of the variables associated with the third hypothesis

\begin{tabular}{lllllll}
\hline Variables code & X11 & X12 & X13 & X14 & X15 & X16 \\
\hline X11 & & $.292(*)$ & & & & \\
X12 & $.292(*)$ & & & &. &. \\
X13 & & & & $.387(* *)$ & & \\
X14 & & & $.387(* *)$ & & & \\
X15 & & & & & & $.583(* *)$ \\
X16 & & & & & $.583(* *)$ & \\
\hline
\end{tabular}

* Correlation at the level of significance $(\alpha \leq 0.05)$.

**Correlation at the level of significance $(\alpha \leq 0.01)$.

5.4 Results of the test fourth hypothesis

Deals with the impact of the application of accounting information for improving performance to the concept TQM and its tools in industrial companies, and consisting of variables affecting the hypothesis of: X17, X18, X19, X20, $\mathrm{X} 21, \mathrm{X} 22$, and X23 (as appear in appendix).

Table 11. the results of the test (T-Test) variables associated with the imposition of the fourth hypothesis

\begin{tabular}{llllll}
\hline Variable code & Mean & Std. Deviation & T Value & (df) & Significant \\
\hline X17 & 4.17 & 0.803 & 32.851 & 40 & 0.000 \\
X18 & 3.39 & 0.666 & 32.102 & 40 & 0.000 \\
X19 & 3.8 & 0.749 & 32.101 & 40 & 0.000 \\
X20 & 3.98 & 0.689 & 36.495 & 40 & 0.000 \\
X21 & 3.98 & 0.612 & 41.081 & 40 & 0.000 \\
X22 & 4.32 & 0.61 & 44.8 & 40 & 0.000 \\
X23 & 4.15 & 0.823 & 31.854 & 40 & 0.000 \\
General Mean & 3.790 & 0.707 & 35.89771 & 40 & 0.000 \\
\hline
\end{tabular}

It notes that the arithmetic average, of the year for the third hypothesis is (3.790) of five points. Which indicates the presence of a trace of the application for the concept TQM and its tools in industrial companies with a high degree. It show the results of the test $(\mathrm{T})$ above it. It must reject the hypothesis of nowhere and accept the alternative hypothesis, where the all the variables of the study appear when the level of significance is less than $(0.05)$. This is to accept the alternative hypothesis, which is; there is a statistically significant relationship trends in the study sample about the impact of the application of accounting information for improving performance to total quality management in industrial companies.

5.4.1 Test the correlation coefficients between the studies variables associated with fourth hypothesis

The results of the table below show the strength and direction of the correlation coefficients between variables. This indicates that the proportional relationship between the variables, as well as the strength of correlation coefficients between variables is medium when the level of significance (0.05) and the level of significance (0.01.)(

Table 12. the results of the analysis of the link between some of the variables associated with the fourth hypothesis

\begin{tabular}{llllllll}
\hline Variables code & X17 & X18 & X19 & X20 & X21 & X22 & X23 \\
\hline X17 & & $.293(*)$ & $.348(*)$ & $.279(*)$ & & & $.490(* *)$ \\
X18 & $.293(*)$ & & $.457(* *)$ & $.348(*)$ & $.331(*)$ & $.395(* *)$ \\
X19 & $.348(*)$ & $.457(* *)$ & & $.524(* *)$ & $.535(* *)$ & & $.331(*)$ \\
X20 & $.279(*)$ & $.348(*)$ & $.524(* *)$ & & $.473(* *)$ & $.376(* *)$ & $.315(*)$ \\
X21 & & $.331(*)$ & $.535(* *)$ & $.473(* *)$ & & & $.404(* *)$ \\
X22 & & & & $.376(* *)$ & & & $.503(* *)$ \\
X23 & $.490(* *)$ & $.395(* *)$ & $.331(*)$ & $.315(*)$ & $.404(* *)$ & $.503(* *)$ & \\
\hline
\end{tabular}

* Correlation at the level of significance $(\alpha \leq 0.05)$.

**Correlation at the level of significance $(\alpha \leq 0.01)$. 


\section{Conclusions and recommendations :}

\subsection{Conclusions}

Through the study, the researchers reached the following conclusions :

1. The application of the concept of TQM that would lead to many benefits for companies applied to it, which represented by the strengthening of the competitive position, increase market share, increase production efficiency, improve the performance and cost reduction.

2. Despite the many advantages that can be achieved total quality management to companies have applied, but application is not without many obstacles that might hinder the successful implementation of a process.

3. There is a clear keenness of by the companies (study sample) to seek towards the implementation of accounting information to apply total quality management, and work to provide all the requirements.

4. The filed study reversed a result that the existence of a statistically significant relationship in the attitudes of the study sample towards the response and support industrial companies of the concept of TQM. Also the availability requirements of the application of the concept of TQM in industrial companies. In addition to the applications obstacles to the system of TQM and its tools in industrials companies. Finally, the impact of the application of accounting information for improving performance to the concept of TQM in industrial companies.

\subsection{Recommendations}

In light of the results of the study, the researchers suggests the following recommendations:

1. There is a need to seek industrial companies operating in Syria, whether in the public sector or the private sector towards the implementation of the comprehensive of total quality management .

2. There is a need to educate the departments of companies and workers in all administrative and technical levels of the importance of the application of total quality management. In addition, to give more attention to hold training sessions for employees, in order to provide staff and technical expertise of qualified and able to apply.

\section{References}

Abu-Nasr, Medhat, (2008). Basics of Total Quality Management TQM, Dar Alfajr, Amman, Jordan.

Al-Hashimi, Mouaed Hassan, (2006). The principles of total quality management and its impact in determining the antecedents Altnavsih- Empirical Study of Kufa in the new cement plant, (Unpublished MA Thesis), University of Kufa, Iraq.

Al-Kassar, Talal A., \& Ahmad, M. (2013). Scientific approach for quality audit to service and productivity enterprises (Applied study in Zarqa University), Zaytuna University, Libya, Semi-annual journal, 3, 255-289.

Al-Saffar, Ahmed Abd Ismail \& Mohammed, Magda Abdel-Latif. (2008). The impact of the application of the philosophy of total quality management in accordance with the internal and external customer perspective on the operating performance of the manufacturing organizations, Journal of Management and Economics, No. (73).

Al-Tai, Raad Abdullah \& Kdadh, Issa. (2009). Total quality management, Second Edition, Dar Yazouri, Jordan.

Alwan, Qasim Naiv, (2005). TQM and the requirements of ISO 9001: 2000, the House of Culture, Amman, Jordan.

Ben Antar, Abdul Rahman. (2008). TQM an orientation competitive in today's organizations, Journal of the Researcher, No. (6).

Haddad, A., Ibrahim. (2009). TQM, Dar AlFikar, Amman, Jordan.

Hendricks, Kevin B \& Singhal, Vinod R. (200). The Impact of Total Quality Management (TQM) on Financial Performance Evidence from Quality Award Winners.

Hussein, Ahmed Hussein Ali. (1997). Advanced Management Accounting (Pricing products- performance evaluation- modern production systems), Shuaa library, Egypt.

Jablonski, Joseph. (1996). Comprehensive Quality Management - Part II. (Translation Abdul Fattah Mr. Nomani), Cairo: Center of professional experience management (PMEC), Egypt.

Jouda, Ahmed Mahfouz. (2004). Total Quality Management (concepts and applications), Dar Wael, Amman, Jordan. 
Kandil, Basil Knight. (2008). The impact of the application of total quality and competitive policies in industrial facilities management system-An Empirical Study on the industrial sector facilities in the Gaza Strip, (Unpublished MA Thesis), Faculty of Commerce, the Islamic University, Gaza.

Kelada, Joseph. (2004). Integration with the re-engineering of total quality management, (Translation Srour Ali Ibrahim Srour), Riyadh: Dar Mars, Saudi Arabia.

Khashoggi, Hani. (2003). Total Quality Management TQM models and obstacles to be applied in the Arab security services, Journal of King Abdul Aziz University, Saudi Arabia, 17 (2), 28-55.

Kumar, S. (2009). Total Quality Management, (1 ${ }^{\text {st }}$ d, $)$, published by: University science press, New Delhi.

Matari, Khaled Saleh. (2007). The impact of the application of total quality management (TQM) in the development of cost-systems applied study of a sample of the industrial sector in the Republic of Yemen, (Unpublished MA Thesis), Faculty of Economics, University of Damascus. Syria.

Naidu, N.V.R., Babu, K.M., Rajendra, G. (2006). Total Quality Management, published by new age international (P) Ltd., UK.

Neogy, Taposh Kumar. (2014). Evaluation of Efficiency of Accounting Information Systems: A Study on Mobile Telecommunication Companies in Bangladesh, Global Disclosure of Economics and Business, 3 (1), 40-55.

Sever, Matt (2007). Scientific reference for quality management. (Translated by Khaled Al Ameri), Cairo, Dar al-Faruq, Egypt.

Shibley, Muslim Allawi. (2006). The possibility of the application of TQM in the Iraqi industrial organization management - a prospective study in the General Company for Petrochemical Industries, Journal of the Faculty of Economics and Management at the University of Basra, Iraq, Management Studies, 1 (2) , 25-52.

Sohail, Sadiq \& Hoong, Teo Boon. (2003). TQM practices and organizational performances of SMEs in Malaysia, An International Journal, 10 (1), 37-53.

Weygandt, Jerry J., Kimmel, Paul D., \& Kieso, Donald E. (2013). Accounting Principles, $11^{\text {th }}$ Edition, Wiley, USA.

Williams, Richard's. (1999). Fundamentals of total quality management. (Translation Jarir) library, Riyadh: Jarir Bookstore, Saudi Arabia.

\section{Appendix 1 \\ Questionnaire \\ Dear Respondent: \\ Greetings:}

The researchers prepared a paper entitled "Studying the accounting information role for the industrial companies' attitudes towards the implementation of total quality management system".

The aim of the researchers to identify trends in your views on companies towards the application of the concept of TQM, in terms of Response and support of these companies for the application of total quality management. The availability of the application of TQM in those industrial companies' management requirements. The obstacles that hinder the successful implementation of total quality management from the perspective of the study sample. The impact of the application of accounting information to total quality management in the performance of these industrial companies.

In order that the researchers have developed a questionnaire containing a set of questions to answer :

\section{$\begin{array}{lllll}\text { Strongly Agree } 5 & \text { Agree } 4 & \text { Not sure } 3 & \text { Disagree 2 } & \text { Strongly Disagree 1 }\end{array}$}

Therefore, you can benefit from the practical side in support of the theoretical side. The researchers estimated fruitful 
cooperation to answer the questions contained in the questionnaire-attached list, and this confirms that the questionnaire designed for scientific research purposes only, and your answers will be the subject of strict confidentiality. In addition, to you our sincere thanks and appreciation...

\section{The researchers}

\section{Section I: personal information and functional :}

Please kindly put signal $(\mathrm{X})$ at the appropriate choice in the table below :

1- Gender: Male Female

2- Scientific specialization: Accounting Business Administration Financial and other banking

3- Qualification: Diploma Bachelor Masters Doctorate

4- Job title: General manager - Managing Director - Financial Director - Internal Audit Manager

5- Years of Experience: As in table below

6- Professional Certificate: As in table below

7- Is your company aims to reach TQM? Either Yes or No.

\begin{tabular}{|c|c|c|}
\hline DESCRIBTIVE & DISTIRBUTION & \\
\hline \multicolumn{3}{|c|}{ FIELD OF THE COMPANY'S BUSINESS................... } \\
\hline \multicolumn{3}{|l|}{ Professional Certificate } \\
\hline \multirow[t]{2}{*}{ Sex } & Male & \\
\hline & Female & \\
\hline \multirow[t]{3}{*}{ Scientific specialization } & Secondary or less & \\
\hline & University degree & \\
\hline & Postgraduate & \\
\hline \multirow[t]{3}{*}{ No. of Employee } & Less than 50 & \\
\hline & $50-300$ & \\
\hline & More than 300 & \\
\hline \multirow[t]{3}{*}{ Years of Experience } & Less3 years & \\
\hline & $3-6$ & \\
\hline & More than 6 & \\
\hline \multirow{2}{*}{$\begin{array}{l}\text { Is your company aims to reach } \\
\text { TQM? }\end{array}$} & Yes & \\
\hline & No & \\
\hline
\end{tabular}




\section{Section II:}

There is in this part set of questions that related to the applied aspect of the study. Please answer these questions put signal $(\times)$ in front of what you see fit:

\begin{tabular}{|c|c|c|c|c|c|c|}
\hline \multirow{2}{*}{\multicolumn{2}{|c|}{$\begin{array}{l}\text { Paragraphs } \\
\text { The responsiveness and support of industrial companies to } \\
\text { TQM system: }\end{array}$}} & \multicolumn{5}{|c|}{ Code } \\
\hline & & \multirow[t]{2}{*}{5} & \multirow[t]{2}{*}{4} & \multirow[t]{2}{*}{3} & \multirow[t]{2}{*}{2} & \multirow[t]{2}{*}{1} \\
\hline $\mathrm{X} 1$ & $\begin{array}{l}\text { The adoption of a democratic leadership model that } \\
\text { allows the participation of workers in setting goals, } \\
\text { decision-making and delegation of authority. }\end{array}$ & & & & & \\
\hline $\mathrm{X} 2$ & $\begin{array}{l}\text { Policies and procedures that ensure the continuous } \\
\text { improvement of each activity of the company's } \\
\text { business activities. }\end{array}$ & & & & & \\
\hline X3 & $\begin{array}{l}\text { The formation of work teams able to solve productivity } \\
\text { problems, and this would lead to cost reduction and } \\
\text { increase productivity. }\end{array}$ & & & & & \\
\hline $\mathrm{X} 4$ & $\begin{array}{l}\text { A clear focus on the needs of the market, which the } \\
\text { company operates, thus achieving outstanding } \\
\text { performance leading to increased market share for the } \\
\text { company. }\end{array}$ & & & & & \\
\hline $\mathrm{X} 5$ & $\begin{array}{l}\text { Develop effective programs for the training and } \\
\text { education of staff in order to perform the functions to } \\
\text { the fullest, and this in turn contributes to reducing } \\
\text { workplace accidents, reduce errors, increase the } \\
\text { effectiveness of operations. }\end{array}$ & & & & & \\
\hline
\end{tabular}

\begin{tabular}{|c|c|c|c|c|c|c|}
\hline \multirow{2}{*}{\multicolumn{2}{|c|}{$\begin{array}{l}\text { Paragraphs } \\
\text { Availability requirements needed by industrial companies } \\
\text { to apply TQM and its tools: }\end{array}$}} & \multicolumn{5}{|c|}{ Code } \\
\hline & & \multirow{2}{*}{5} & \multirow[t]{2}{*}{4} & \multirow[t]{2}{*}{3} & \multirow[t]{2}{*}{2} & \multirow[t]{2}{*}{1} \\
\hline X6 & $\begin{array}{l}\text { The availability of support and support from senior } \\
\text { management. }\end{array}$ & & & & & \\
\hline $\mathrm{X} 7$ & $\begin{array}{l}\text { Availability capable of teamwork and problem-solving } \\
\text { teams, which may be extremely complex. }\end{array}$ & & & & & \\
\hline $\mathrm{X} 8$ & $\begin{array}{l}\text { The availability of methods and policies, and } \\
\text { procedures that govern the effective design of the } \\
\text { goods in terms of the process of selection of the } \\
\text { designers for materials, machinery and equipment. }\end{array}$ & & & & & \\
\hline X9 & $\begin{array}{l}\text { The availability of productive program works to } \\
\text { determine the necessary processes to inputs, outputs, } \\
\text { control and measurement. }\end{array}$ & & & & & \\
\hline $\mathrm{X} 10$ & $\begin{array}{l}\text { The company's ability to develop criteria to measure } \\
\text { performance for the quality of products and } \\
\text { management practices in the company's measurement. }\end{array}$ & & & & & \\
\hline
\end{tabular}




\begin{tabular}{|l|l|l|l|l|l|l|}
\hline Paragraphs & \multicolumn{2}{l|}{ Code } & & \\
\hline $\begin{array}{l}\text { Obstacles to the application of total quality management } \\
\text { and its tools in industrial companies: }\end{array}$ & 5 & 4 & 3 & 2 & \\
\hline $\mathrm{X} 11$ & $\begin{array}{l}\text { Deficiencies in the vision and commitment of senior } \\
\text { management. }\end{array}$ & & & & & \\
\hline $\mathrm{X} 12$ & $\begin{array}{l}\text { It may be the company's culture and management style } \\
\text { an important role in impeding the application of total } \\
\text { quality management process successfully. }\end{array}$ & $\begin{array}{l}\text { Deficiencies in the accounting information system used } \\
\text { in the company. }\end{array}$ & & & & \\
\hline $\mathrm{X} 14$ & $\begin{array}{l}\text { Lack of sufficient communication between departments } \\
\text { with each other. }\end{array}$ & & & & \\
\hline $\mathrm{X} 15$ & $\begin{array}{l}\text { Shortcomings in the organizational structure of the } \\
\text { company in terms of total quality management } \\
\text { activities. }\end{array}$ & & & & & \\
\hline $\mathrm{X} 16$ & Lack of work teams and leaders trained enough. & & & & & \\
\hline
\end{tabular}

\begin{tabular}{|c|c|c|c|c|c|c|}
\hline \multirow{2}{*}{\multicolumn{2}{|c|}{$\begin{array}{l}\text { Paragraphs } \\
\text { The impact of the application of accounting information to } \\
\text { TQM in improving performance of industrial } \\
\text { companies: }\end{array}$}} & \multicolumn{5}{|c|}{ Code } \\
\hline & & \multirow[t]{2}{*}{5} & \multirow[t]{2}{*}{4} & \multirow[t]{2}{*}{3} & \multirow[t]{2}{*}{2} & \multirow[t]{2}{*}{1} \\
\hline $\mathrm{X} 17$ & $\begin{array}{l}\text { The use of TQM may achieve the desired benefit in the } \\
\text { process of cost reduction. }\end{array}$ & & & & & \\
\hline $\mathrm{X} 18$ & $\begin{array}{l}\text { Total Quality Management is working to strengthen the } \\
\text { competitive position of companies by focusing on } \\
\text { providing products or high quality services to } \\
\text { customers, thereby increasing the market share of the } \\
\text { company. }\end{array}$ & & & & & \\
\hline X19 & $\begin{array}{l}\text { The use of total quality management helps to reduce } \\
\text { and mastery of administrative processes within } \\
\text { accounting information in the company. }\end{array}$ & & & & & \\
\hline $\mathrm{X} 20$ & $\begin{array}{l}\text { Total Quality Management is working to increase } \\
\text { efficiency and productivity by reducing waste and loss } \\
\text { in inventory, reduce errors and operational processes } \\
\text { depending on accounting information. }\end{array}$ & & & & & \\
\hline $\mathrm{X} 21$ & $\begin{array}{l}\text { The use of Total Quality Management helps companies } \\
\text { to continuous assessment of the operations to be able to } \\
\text { develop a strategy for continuous improvement. }\end{array}$ & & & & & \\
\hline $\mathrm{X} 22$ & $\begin{array}{l}\text { The application of total quality management to increase } \\
\text { production efficiency, through accounting information } \\
\text { which in turn leads to the achievement of the benefits } \\
\text { and savings in costs and timelines production } \\
\text { processes. }\end{array}$ & & & & & \\
\hline $\mathrm{X} 23$ & $\begin{array}{l}\text { TQM implementation leads to reduced customer } \\
\text { complaints through the full understanding of their } \\
\text { needs and work to achieve them. }\end{array}$ & & & & & \\
\hline
\end{tabular}

